\title{
Designing interaction tasks in Second Life for Chinese as a foreign language learners: A preliminary exploration
}

\author{
Yu-Ju Lan \\ Department of Applied Chinese Languages and Culture, National Taiwan Normal University, Taiwan
}

Yu-Hsuan Kan

Graduate Institute of Information and Computer Education, National Taiwan Normal University, Taiwan

Indy Y.T. Hsiao, Stephen J.H. Yang,

Department of Computer Science and information Engineering, National Central University, Taiwan

\section{Kuo-En Chang}

Graduate Institute of Information and Computer Education, National Taiwan Normal University, Taiwan

\begin{abstract}
The aims of this research were to develop guidelines for designing interaction tasks for learners of Chinese as a foreign language (CFL) and to investigate the attitudes of CFL learners toward a full CFL class in Second Life (SL). Three research questions were addressed in this research: (1) what are the attitudes of CFL learners toward the language learning tasks in SL? (2) what kinds of social interactions emerge from learning activities in a CFL class in SL? (3) how do those activities benefit CFL learners in the learning of Chinese in SL? Two studies were conducted to tackle these questions. The cognition, usage, and expansion (CUE) model was proposed based on the findings obtained from study 1 and then implemented and evaluated in study 2. The findings of study 2 indicated that the activities run in the CUE model were effective at motivating CFL beginners and improving their oral communication and social interactions. Based on the video data analysis, three criteria were proposed for designing learning activities. Suggestions are also made for future research on CFL teaching/learning in SL.
\end{abstract}

\section{Introduction}

The ability of Second Life (SL) to establish a community and assist the breaking down of barriers to communication that might exist in asynchronous web-based learning environments and even in face-toface learning situations has been drawing special attention from many researchers and educators since 2003 (Conklin, 2007; Dalgarno, Lee, Carlson, Gregory, \& Tynan, 2011; Jarmon, Traphagan, Mayrath, \& Trivedi, 2009). It has also fostered a growing interest in the use of SL as an educational environment that satisfies the needs of alternative educational opportunities due to the increasing population of nontraditional students who are unable to attend classes because of work, family, or traveling commitments (Oblinger \& Oblinger, 2005).

With regard to language education, the major reason for the rapid increase in language learning in SL is its potential to provide an immersive environment in which foreign language (FL) or second language (L2) learners can become actively, collaboratively, and socially involved in authentic language learning activities (Cooke-Plagwitz, 2008; Henderson, Huang, Grant, \& Henderson, 2009; Hundsberger, 2009; Liou, 2012; Peterson, 2008; Stevens, 2006; Thorne, Black, \& Sykes, 2009). According to Lave and Wenger (1991), we learn by becoming part of a community of practice. FL learners will only become fluent if they have opportunities to engage themselves in authentic linguistics social practices, as suggested by the hypothesis of second language acquisition (SLA) that states that scaffolding and meaningful social interactions in a natural and authentic condition is an effective learning approach for FL learners (Krashen, 1981; Long, 1996; van Lier, 1996).

Hew and Cheung (2010) categorized three main research topics in their survey of the use of threedimensional immersive virtual worlds in K-12 and higher education settings: affective domain, learning outcome, and social interaction. Furthermore, with respect to research on integrating SL in FL learning, "activity or task design for social interaction" is also one of most burning issues (e.g., Collentine, 2011; Deutschmann, Panichi, \& Molka-Danielsen, 2009; Jauregi et al., 2011; Liou, 2011). For example, 
Deutschmann, Panichi, and Molka-Danielsen (2009) conducted a two-stage action research on designing activities for English oral participation in SL. They argued that meaning-focused tasks, which involve authenticity and collaborative elements, have a direct impact on learner interactions. Liou (2011) used four tasks in college computer-assisted language learning courses to examine how SL benefited English learning and teaching. She found that SL can easily establish an authentic environment for communication. In addition, by integrating appropriate tasks with sound pedagogical purposes, SL can support the multimember community in advancing toward language objectives or sense-making in student learning. Jauregi, Canto, de Graaff, Koenraad, and Moonen (2011) investigated the advantages of some specific types of tasks, and proposed a task design grid for task development and evaluation. They also explored whether the virtual world enhances interactions.

Studies of task design for enhancing interactions have explored the Chinese language only sparsely compared with other languages such as English and Spanish. Chinese is the most widely used language worldwide, being spoken by approximately 846 million people (Lewis, Simons, \& Fenning, 2013). The bilingual topic of TIME Asia issued on June 26, 2006, entitled "学汉语 Get Ahead, Learn MandarinThe language is now becoming a must-have asset for ambitious students and professionals hoping to ride the Chinese boom to success" (TIME Asia, 2006) provides a reason for the rapidly increasing number of learners of Chinese as a FL (CFL) worldwide. It is noteworthy that many of the global CFL learners are unable to join conventional CFL classes due to personal reasons. It is therefore essential to explore the approaches to designing effective tasks/activities for CFL learning in SL, so learners can reach their desired learning goals (Dalgarno \& Lee, 2010). Additionally, the concrete implementation procedure of language learning tasks in SL, especially for L2 beginners, should be confirmed rather than only providing a brief guideline (Jauregi et al., 2011) or solely arguing the importance of providing L2 learners with meaning-oriented activities (Chen, 2010; Liu, 2010). Thus, it is useful for both language teachers to guide L2 learners and researchers to design appropriate learning activities.

Chen (2010) and Henderson et al. (2009) investigated Chinese learning in SL, and raised some arguments regarding the impacts of the activity features on CFL learning. Chen suggested that the instructor needs to develop pedagogically sound tasks to motivate learners to learn. Moreover, Henderson and colleagues found that students were more confident at engaging in tasks that were similar to those in the lesson activities run in traditional classes. However, both of these investigations focused on the affective domain rather than on an activity or task design; the former emphasizes the attitudes of CFL learners toward SL, while the latter aims to determine how learning Chinese in SL improved the self-efficacy beliefs of CFL learners. The kinds of activities that can be identified as pedagogically sound or appropriate for CFL learning in SL remain to be explored.

The role played by SL in the CFL syllabus seems to be monotonic in most research on CFL or other target language learning. CFL learning in SL is usually viewed as a supplementary activity to or just one of the teaching models for regular FL classes (Chen, 2010; Grant, 2010; Henderson et al., 2009; Liu, 2010). Few studies have explored the approaches to designing tasks or activities to be implemented in an independent CFL class that is conducted entirely in SL, benefiting those learners who prefer distant learning due to either practical constraints against attending traditional, regular CFL classes, or to personal needs in lifelong learning.

Taking into account the necessity of conducting CFL classes in SL and the dearth of relevant research on designing and evaluating Chinese learning tasks to enhance social interactions in virtual worlds, the aim of the current study was to elucidate suitable approaches for designing CFL learning tasks and the social interactions emerging from those tasks accomplished in SL. Three research questions were addressed in this research: (1) what are the attitudes of CFL learners toward the language learning tasks in SL? (2) what kinds of social interactions emerge from learning activities in a CFL class in SL? (3) how do those activities benefit CFL learners in the learning of Chinese in SL?

Two studies were conducted to answer these research questions. In the first study (study 1), eight CFL beginners were invited to attend eight 2-hour CFL beginner classes between November and December in 2009 , each participant attending one class. The social interactions and oral conversations were observed to clarify the affordances and deficiencies in the SL environment. In the second study (study 2), based on the experience and findings of study 1 , a three-stage activity model was proposed, implemented, and then evaluated, between May and early July in 2010. The following sections briefly present studies 1 and 2 of 
this preliminary research, analysis of the results, a discussion thereof, and the conclusions of these studies.

\section{Study 1: a background observation on teaching CFL in SL}

Study 1 served to provide background observations with which to investigate what activities should be run to teach/learn Chinese in SL and what kinds of interactions would emerge from those activities. The aim of this study was to determine how distant CFL learners behave and to establish the kinds of activities that would be appropriate to include in a CFL-for-beginners class in the virtual world. All of the participants were recruited from SL citizens who were interested in Chinese learning, and were not previously known to the CFL teachers and researchers participating in this study. As mentioned above, this study took place over a 2-month period in 2009, and comprised a total of eight, 2-hour sessions. All of the classes were videotaped with screen recording software (Camstudio) and subsequently analysed to identify how CFL learning activities were run in SL and how different activities affected the social interactions in the virtual world, as well as the perspectives of CFL teachers on SL as a CFL teaching platform.

\section{Methods}

Design

Study 1 employed a qualitative approach. Both video data and teacher journals were collected. The foci were the discourse and social interactions between CFL beginners and teachers while participating in/running learning activities.

\section{Participants}

Eight college-level SL citizens from seven countries (South Korea, the Philippines, the UK, Indonesia, Vietnam, Denmark, and Brazil) were recruited for this study via a participant recruitment announcement in SL. All the participants were CFL beginners, SL players, and each separately undertook a single 2-hour CFL lesson. In addition, two CFL teachers who worked in pairs voluntarily participated in the CFL teaching.

\section{Instruments}

Four topics from everyday Chinese life were chosen as the teaching materials: (a) check into a hotel, (b) transportation and location, (c) food and culture issues, and (d) nationality and self-introduction. Each topic formed the theme of a teaching package, and a total of four packages were used in study 1, each of which was re-taught once. All of the teaching packages were taught following identical procedures which will be described in next section. In addition, those teaching packages were accompanied by SL scenes, such as a restaurant and a hotel, in a Virtual Living Laboratory developed by the Institute for Information Industry (III) as shown in Figure 1. III is a non-governmental organization with the aim to support the development/applications of the information industry, as well as an information society in Taiwan (http://web.iii.org.tw/).

a

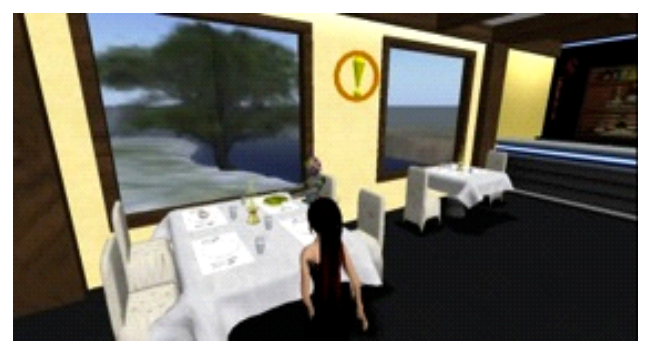

b

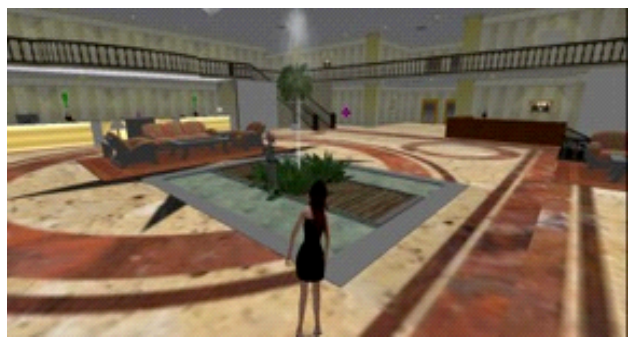

Figure 1. Scenes in SL: (a) the restaurant and (b) the lobby of a hotel. 


\section{Procedure}

The classes took place between November 17th and December 21st in 2009, and comprised eight, 2-hour sessions. Each participant separately attended a single lesson. Soon after each lesson finished, both CFL teachers wrote a teaching journal that reflected on their teaching and recorded the difficulties they had encountered in the lesson. The selected activity or topic was based on the landmark availability provided by III during study 1 . Figure 2 depicts the brief procedure of study 1 . Additionally, the detailed in-class teaching activities include the following steps:

- Step 1: Make sure the sound and microphone system work properly as well as break the ice (or get the class talking).

- $\quad$ Step 2: Introduce Hanyu Pinyin system.

- $\quad$ Step 3: Warm up and interpret the learning goal of the teaching package.

- $\quad$ Step 4: Introduce new skills (vocabulary and sentences).

- $\quad$ Step 5: Run different practices (e.g., role playing) in an authentic landmark, such as in a restaurant or airport.

- $\quad$ Step 6: Accomplish a learning task.

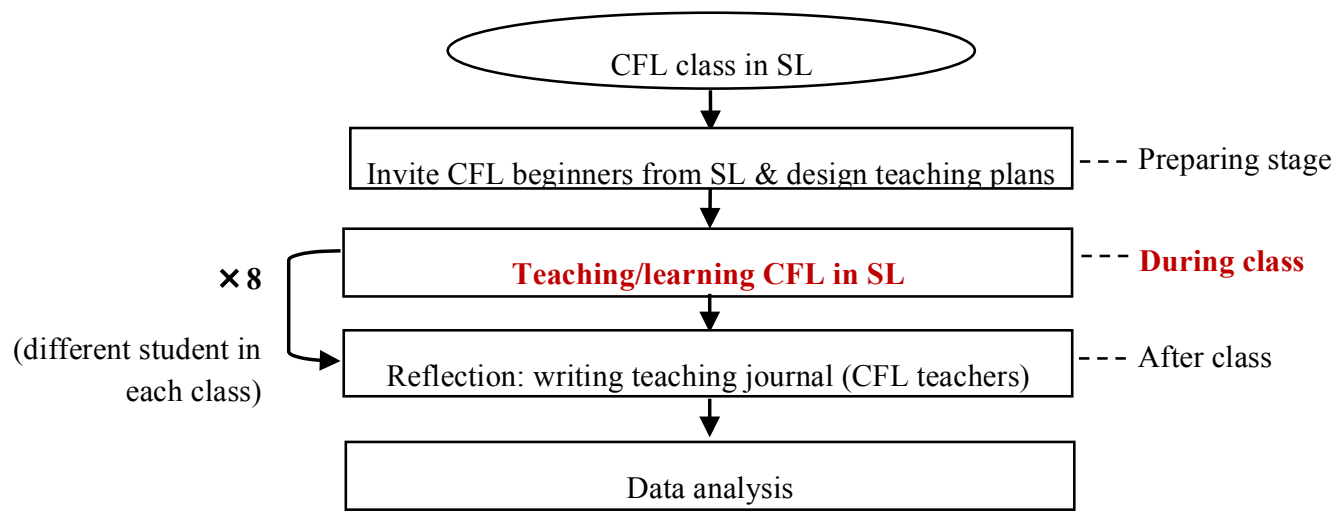

Figure 2. Procedure of study 1.

\section{Results}

The data collected for further analysis in study 1 were the teaching journals and teaching videos. The analysis focused on (1) the activities run in the CFL class in SL, (2) the social interactions emerging from those activities, (3) the effective and ineffective activities for CFL teaching in SL, and (4) the viewpoint of Chinese teachers on CFL teaching in SL.

Regarding the teaching activities and social interactions, in total, seven kinds of teaching activity were identified: interpretation (I), modelling (M), listening and repeating (LR), drills (D), total physical response (TPR), presentation (P), and role play (RP). Three between-subjects categories were identified for interactions in SL: inter-avatar (IA), avatar-context (AC), and avatar-context-avatar (ACA); where "context" represents the objects in SL, including all of the SL buildings and teaching aids made by the CFL teachers, such as note cards and Web PowerPoint presentations. In addition, the activity purposes could be classified into four categories: explanation (E), memorization (M), implication (I), and negotiation $(\mathrm{N})$.

Unfortunately, most of the activities were teacher-centred instructions or practicing for explaining concepts (i.e., explanation) or memorizing learning materials (i.e., memorization), even though CFL teachers' original attempts were to provide CFL beginners with student-centred learning as described in the journals. In addition, due to the CFL learners' lack of knowledge of Chinese pronunciation and characters, Hanyu Pinyin rules were introduced at the beginning of each class. The text function in SL was used as a medium for the introduction. And the text function of SL was often used by CFL learners to type English for confirmation and to type Hanyu Pinyin by the teacher to help the CFL learners to understand the instructions during class. One CFL teacher noted this situation in her journal as an instance of text-based communication. The teacher mentioned that the learners' attention was easily distracted 
toward other stimuli in SL or lowered their learning motivation (on December 9, 2009) because sometimes the participants left with some other foreign avatars to go somewhere else.

As to efficiencies of learning activities for CFL teaching in SL, the fluency of inter-avatar interactions during executing learning activities was a matter for concern. Based on the turns and moves needed for grounding in conversation (Clark \& Brennan, 1993), only some of the social interactions were fluent. Many conversations were identified with the struggle to reach the conversation goals. It was also found that the relevance of the learning contents and the virtual scenes in SL greatly influenced CFL teaching and learning, except in cases where there was a problem with the Internet connection quality.

When it came to teachers' opinions of SL as a CFL teaching environment, the two CFL teachers thought that SL provided a promising environment in which they could easily lead learners to participate in authentic learning activities that are situated in "real world" locations. The learners were able to see and do things that would not be possible in a real conventional CFL classroom. For instance one of the participating CFL teachers expressed in her journal the excitement that she experienced as a result of the genuine interaction between the virtual context and the avatars, as follows

This is a test drive of teaching a new topic in different way, also the first time I directed students "learning by doing". And it has been proved effective and gets results. For example, in the past when teaching "how to take a bus", we used the pictures helped students make sentence like "I will get there by foot," "I will go by bus." But it seemed abstract to students. Now students learn "I will go by bus" by actually doing it in the teaching try which makes teaching try which makes teaching an exciting process. $(12 / 17 / 2009)$

Some problems/limits of conducting CFL lessons in SL were also encountered, such as some simple but useful gestures or body language that are helpful for language learning and are very common in everyday real life are not easily achieved in SL (Hundsberger, 2009). This particular concern was raised by one of the CFL teachers, as follows:

However, we found students have never learned Pinyin before, so it's hard for them to read it out. Besides, it's hard for them to pronounce tones correctly because they cannot see teachers' mouth motion or body language. (11/17/2009)

In summary, SL technology has great potential in CFL teaching and learning, but there is still room for improvement. Two possible improvements are (1) to promote the learning motivation and interaction fluency of students using well-designed activities, from teacher-centred to student-centred, and increase the consistency between learning content and SL context; and (2) to sufficiently cultivate the prior abilities of CFL learners before they are required to accomplish assigned language learning tasks.

\section{Study 2: preliminary implementation and evaluation of a three-stage CFL teaching model (cognition, usage, and expansion) in SL}

Study 2 implemented a revised teaching procedure of a teaching package based on both task-based learning (TBL) and the spiral material design principle to tackle the problems encountered in study 1 and to better answer the research questions. TBL is effective in maintaining motivation such that the learners generally accomplish the given tasks that contribute to meaningful interactions in the FL (Ellis, 2000; Sadler \& Nurmukhamedov, 2008). Furthermore, according to Krashen (1981), van Lier (1996), and Long (1996), meaningful interactions are especially important for acquiring the target language by FL learners. The linguistic output of FL learners (speaking or writing) while accomplishing a task is also important for acquiring the target language (Swain, 1995). However, based on the findings of study 1, poor prior skills of FL learners in the Chinese language hinder them from successfully accomplishing the learning tasks and producing the expected linguistic output. This problem was addressed by applying the spiral material design principle (Bruner, 1977) when revising the teaching packages, where "spiral" means that the learning contents (key words and sentence structures) were reviewed via various activities after they were first introduced to the CFL learners. Thus, by combining TBL and the spiral design concept, the teaching package was redesigned as a three-stage model: cognition, usage, and expansion (CUE). The language 
focuses (words and sentence patterns) of each teaching package were taught in the cognition stage, then reviewed via individual task accomplishments, and were ultimately re-reviewed via transferring what had been learned via cooperative TBL in different contexts. The design considerations, implement tips, and the teacher's role at each stage are described briefly below.

\section{The CUE model}

Stage 1: cognition-prior skill development

The cognition stage introduces the skills that will be needed in the subsequent usage and expansion stages. Those skills include Chinese characters and functional sentence patterns. The objective of the cognition stage is to cultivate the basic Chinese skills of CFL learners in order to enhance their social interactions in the subsequent task-accomplishing process. The activities performed in this stage were first teacher-centred, and then moved to teacher-guided practices, such as TPR, pair work, or RPs. While practicing, the CFL teacher acted as a supervisor to provide CFL learners with timely aids.

Figure 3 depicts a TPR paired activity that allowed the students to practice the Chinese words and sentences about "direction". In this activity, one participant was asked to move to the back of the classroom, and the other stayed with the teacher at the front of the classroom. Then, the teacher hid an object (e.g., by putting "小籠包, xiao3 long2 bao, steamed dumpling" on the chair in the first row), and then the student who was with the teacher gave the directions to the other one to help him reach the hidden object, e.g., "往前直走, 再往前直走, 左轉, 往前 (Go straight ahead. Keep going and turn left. Then go straight ahead.)" During the activity, all the commands were given by the beginners, and the teacher only got involved when necessary.

The participant is looking for the hidden object.

The participant is giving commands.

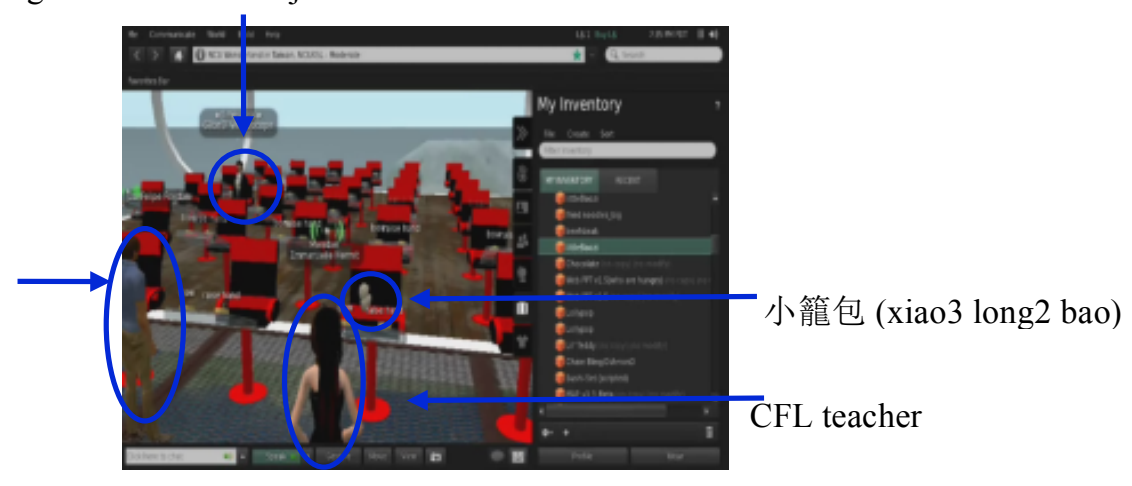

Figure 3. An example of TPR pair activity done in cognition stage.

Stage 2: usage-individual task-based practice

The objectives of the usage stage are to encourage each participant to actively use what they learned during meaningful interactions and to prepare each CFL learner to be ready for the cooperative learning in the next (expansion) stage by accomplishing individual tasks. The activities in this stage were studentcentred and task-based. Each CFL learner was asked to accomplish assigned tasks, while the teacher was responsible for helping the learners to accomplish these tasks successfully.

Figure 4 represents a task performed by a participant. There was a map and a photograph of a supermarket (location C) taken by a participant in SL. In this activity, the CFL teacher showed the participants a map with unknown locations, and then asked each participant to choose one. The participants performed the task by approaching the chosen location and then taking a picture of it. Afterwards, they came back to the teacher, showed the pictures, and reported how he/she got there, e.g., " 出去後左轉, 往前直走, 右轉, 往前直走, 右轉, 超市在圖書館右邊 (Go out and turn left. Go straight ahead. Turn right. Keep going and turn right. The supermarket is on the right side of the library.)" 


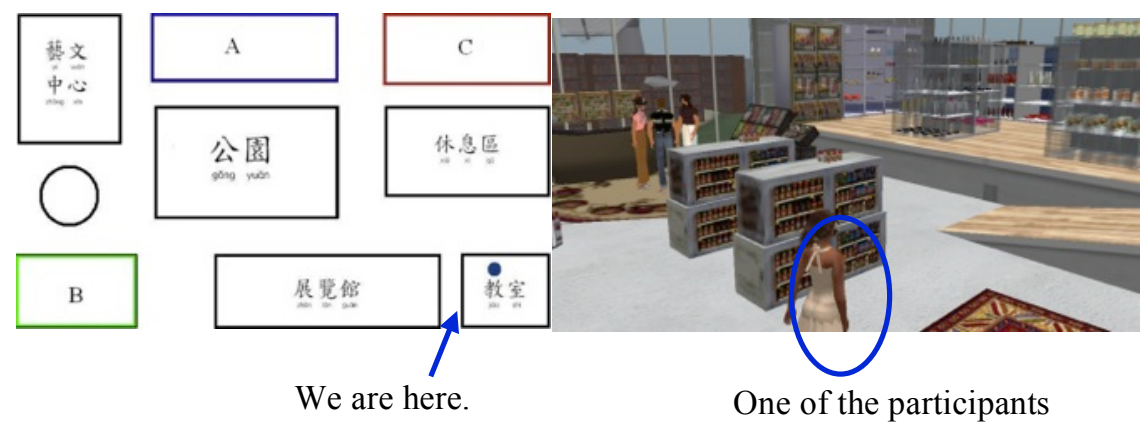

Figure 4. An example of individual task performing in the usage stage.

Stage 3: expansion - cooperative problem-solving practice

The objective of the expansion stage is to provide CFL learners with opportunities to transfer what was learned in the two previous stages to various contexts. It implements various approaches (interaction and negotiation) to induce IA discussion, negotiation, and cooperation. Problem-solving-based tasks for cooperative learning were the main learning activities designed to fulfil that goal. After being informed of the problems, the participants discussed and negotiated with partners to use strategies to deal with them. Then each avatar played by the learner would try to accomplish the assigned missions. Finally, all avatars joined together to discuss and confirm whether they had successfully solved the given problems.

Figure 5 shows an example of cooperative problem solving activities in expansion stage. In this activity, the teacher gave all the participants a note card with a problem about colours and clothes. All the participants were instructed to a garment shop (Freebies, a store landmark in SL in which one can get lots of things for free, including clothes, shoes, different body shapes, tattoos, food, drink, furniture, and even houses) to buy their outfit with various colours and to try on these clothes. Importantly, the total number of colours and types of clothes they bought needed to meet the requirements described in the task.

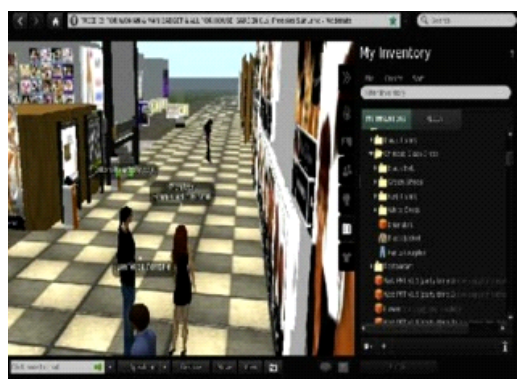

Figure 5. Participants are buying clothes in Freebies.

\section{Methods}

Design

Various data were collected during study 2. Those data were analysed via different qualitative approaches: content analysis for analysing participants' comments, homework performance, online class videos which were taped via the screen-recording software (Camstudio), and teacher-participant email communication; and descriptive statistics (here was percentage calculation) for analysing participants' after-class evaluation (obtained by completing a feedback questionnaire after each lesson). The data analysis focuses on the attitudes of CFL learners toward Chinese learning in SL, their in-class oral performances, homework performance, social interactions, and class engagement.

\section{Participants}

Four CFL learners from four countries (Trinidad, India, Canada, and Chile) participated in study 2; one was a full-time student and the others were part-time students, and they were all CFL beginners and have a common language, i.e., English. They got the study information via a broadly distributed email of the participant recruit announcement sent by the authors. All learners except one (who had used SL for one month) were novice SL users. Their aims for attending the CFL class were preparing for future jobs, an 
interest in language learning, a requirement for traveling in China, and just for fun. One CFL teacher voluntarily took part in the teaching for this study.

\section{Instruments}

1. Pre-program survey. The pre-program survey included five items asking the participants about background information, including what their expectations for Chinese learning in SL were, what synchronous and asynchronous online language learning activities they preferred or could accept, what their Chinese learning plan was, and how they felt about using SL in Chinese learning.

2. Feedback questionnaire. A 4-point Likert scale (scored from "strongly disagree" to "strongly agree" as 1 to 4, respectively) was used as the answer format for this questionnaire (see the question items in Table 1). The questionnaire was developed by the authors. All the dimensions and items included in the questionnaire followed the requirements of the certification-specification clauses for both e-Learning service and e-Learning courseware developed by the e-Learning quality certification center (2007a, 2007b). The questionnaire comprises 7 dimensions and 17 items, as listed in the first and second columns of Table 1. Note that each dimension was also structured with an open-ended question, which allowed for an in-depth understanding of the attitudes of the participants toward Chinese learning in virtual worlds.

3. Teaching and reviewing materials and after-class homework. In total, three units of three lessons (a total of nine lessons) were developed for study 2: unit 1 你餓了嗎 (Ni3 e4 le ma; "are you hungry?"); unit 2 怎麼去 (Zen3 me qu4; "how do you get there?"); and unit 3 顔色派對 (Yan2 se4 pai4 dui4; "colour party"). All of the teaching materials used in each class were created as Web PPTs to share in the class. The reason of using Web PPTs in SL is to help CFL beginners obtain basic skills, such as essential vocabulary and sentence patterns, and be ready for the later socially interactive activities (Lan, Sung, Chang, 2007; 2009). Figure 6 gives an example of using a Web PPT to teach about colours and clothes in unit 3 "顔色派對." Furthermore, a multimedia PPT with the same content as used in the class was emailed to the participants after each class, in which the audio information of both the Chinese and English versions of the words and sentences were added to help the CFL learners review after the class what they had learned in the class. An e-homework worksheet was also sent to the participants by email, which required students to complete three tasks: a picture-vocabulary matching task, a true-false listening task, and an oral recording. All of the participants were asked to do the homework, and then to submit it to the teacher before the next class started.

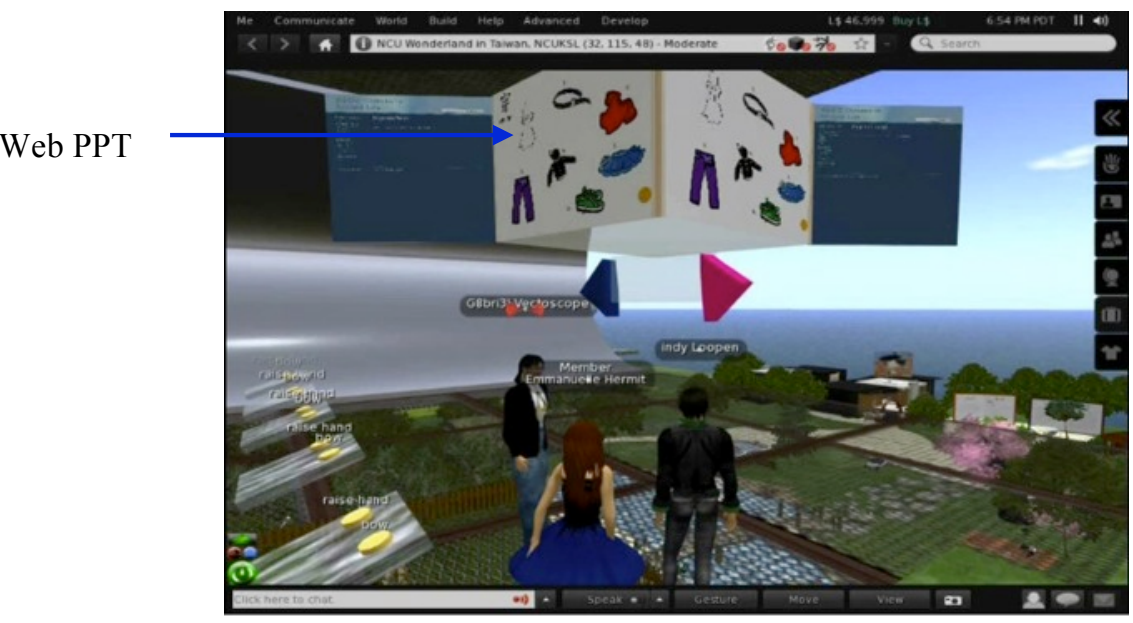

Figure 6. A Web PowerPoint used in unit 3 “顏色派對”

Procedure: implementation procedures for the CUE model

Given the finding of study 1 that the prior skills of CFL learners is important to social interactions in the teaching process, a pre-CUE stage was added to the aforementioned three CUE stages (cognition, usage, and expansion) in order to prepare both the SL environment and CFL beginners for the follow-up teaching and learning activities in the three teaching stages. 
After the pre-CUE stage, three units were taught from the middle of May to early July in 2010. Each unit contained three lessons, which were taught following the three stages of CUE (i.e., lessons 1, 2, and 3 were taught in the cognition, usage, and expansion stages, respectively). Each lesson was taught for 1 hour per week. Therefore, excluding the time for the pre-CUE training, the CFL class lasted a total of 9 hours over 9 weeks. Furthermore, after each lesson finished, students were given homework and were asked to return it via email at the post-CUE stage. Then, how the participants performed homework, their error patterns, and (especially) the mispronounced tones were evaluated. A questionnaire was also mailed to the participants to collect their comments and feedback on the CFL class in SL. In addition to the data mentioned above, the teaching process was also videotaped for further analysis. Figure 7 shows the CUE model implementation procedures.

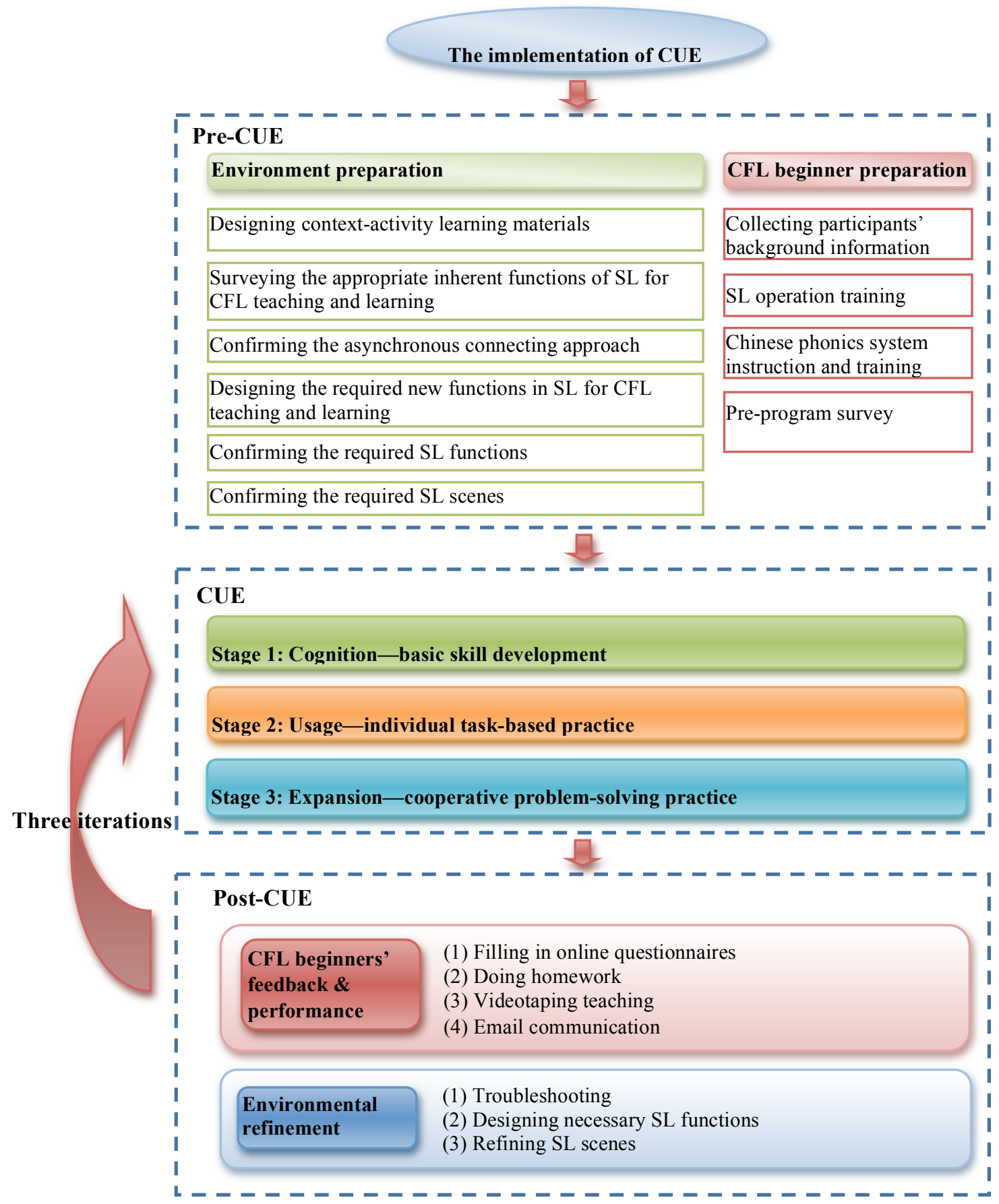

Figure 7. The CUE model implementation procedure in study 2. 


\section{Results}

The collected data were analysed using a qualitative approach in order to answer the three research questions and to ascertain the effectiveness of the CUE model in meeting the requirements of CFL teaching in virtual worlds for future expanded research. The analysis focused on the attitudes of CFL beginners toward the teaching model, class engagement, social interaction, and the performances of the CFL learners. Reflection on the teaching process and possible problem-solving strategies proposed based on the discussion between the researcher and CFL teachers were deemed to be important issues of concern. The results from the three units during the 10-week CUE implementation are described below.

Research question 1: What are the attitudes of the CFL learners toward the language-learning tasks in SL?

Table 1 presents the results derived from the responses of the subjects who completed the questionnaire survey administered after each class, which was designed to elucidate the attitudes of CFL beginners toward the Chinese class via their self-evaluation and self-reports. Four mean scores are listed in Table 1: I, II, and III stand for the rating obtained in Units 1, 2 and 3; respectively, "All" is the average of the three mean scores. Those scores indicate that all of the participants responded positively in all of the seven dimensions throughout the classes, such as in both of the learning and teaching efficiency evaluations (Table 1). Below is an example of the positive comments from one of the participants:

I enjoyed them all, in the food section the restaurant part was a good example of how one can utilize a familiar situations to provide additional learning cues. The How to Go assignment and the use of the city was a good problem solving exercise in the sense of constructing sentences and utilizing the Chinese Characters. Party time, although brief was clearly intended as an exercise in which the problem solving and cooperation among peers was present. The usage of clothing and colors and the transfer and wearing of such was a good idea for an interactive activity.

Table 1

Analysis of the feedback questionnaire

\begin{tabular}{|c|c|c|c|c|c|}
\hline \multirow{2}{*}{ Dimension } & \multirow{2}{*}{ Items } & \multicolumn{4}{|c|}{ Mean scores } \\
\hline & & I & II & III & All \\
\hline \multirow{4}{*}{$\begin{array}{l}\text { Learning efficiency } \\
\text { evaluation }\end{array}$} & 1. This class benefited my learning of Chinese. & 4.0 & 4.0 & 4.0 & 4.0 \\
\hline & 2. I successfully learned what the teachers taught in this class. & 3.0 & 3.7 & 3.0 & 3.2 \\
\hline & $\begin{array}{l}\text { 3. I have confidence in using what I have learned in this class to } \\
\text { communicate with a Chinese friend in a similar situation. }\end{array}$ & 2.8 & 3.0 & 3.3 & 3.0 \\
\hline & 4. I worked hard in the class. & 3.7 & 4.0 & 3.7 & 3.8 \\
\hline \multirow{3}{*}{$\begin{array}{l}\text { Teaching efficiency } \\
\text { evaluation }\end{array}$} & 1. The teacher delivered the learning materials in a smooth flow. & 3.8 & 4.0 & 4.0 & 3.9 \\
\hline & $\begin{array}{l}\text { 2. The vocabulary of this class is appropriate (neither too much nor too } \\
\text { little, neither too difficult nor too easy). }\end{array}$ & 3.8 & 4.0 & 4.0 & 3.9 \\
\hline & $\begin{array}{l}\text { 3. Teacher's explanation for the learning materials was clear and } \\
\text { helpful. }\end{array}$ & 3.8 & 4.0 & 4.0 & 3.9 \\
\hline \multirow{3}{*}{$\begin{array}{l}\text { Quality } \\
\text { evaluation }\end{array}$} & $\begin{array}{l}\text { 1. The materials used in this class helped me follow the teacher's } \\
\text { teaching flow. }\end{array}$ & 3.8 & 4.0 & 4.0 & 3.9 \\
\hline & $\begin{array}{l}\text { 2. The materials used in this class provided me with good examples to } \\
\text { practice Chinese. }\end{array}$ & 4.0 & 4.0 & 4.0 & 4.0 \\
\hline & 3. The materials used in this class looked good on the SL interface. & 3.7 & 4.0 & 3.7 & 3.8 \\
\hline \multirow[b]{2}{*}{ Peer communication } & 1. The learning activities improved my communication skills. & 4.0 & 4.0 & 3.7 & 3.9 \\
\hline & $\begin{array}{l}\text { 2. I feel that it is good and cool to communicate with my learning peers } \\
\text { in SL. }\end{array}$ & 3.8 & 4.0 & 4.0 & 3.9 \\
\hline $\begin{array}{l}\text { Interface } \\
\text { operation }\end{array}$ & $\begin{array}{l}\text { 1. I can successfully operate the SL interface to complete online } \\
\text { Chinese learning activities. }\end{array}$ & 3.0 & 4.0 & 4.0 & 3.7 \\
\hline \multirow{3}{*}{ Homework evaluation } & $\begin{array}{l}\text { 1. The after-class homework helped me to effectively review what I } \\
\text { learned in the class. }\end{array}$ & 3.8 & 4.0 & 4.0 & 3.9 \\
\hline & 2. I did a good job with my homework. & 2.7 & 4.0 & 3.8 & 3.5 \\
\hline & 3. I had no problems completing the assigned homework. & 3.8 & 4.0 & 4.0 & 3.9 \\
\hline $\begin{array}{l}\text { Personal review } \\
\text { evaluation }\end{array}$ & 1. I have a good plan to review what I learned in this class. & 3.5 & 3.3 & 3.8 & 3.5 \\
\hline
\end{tabular}


However, the confidence of the students in using the learned skills to communicate with Chinese friends was insufficient even though their confidence increased gradually during the study (the third item in the dimension of "learning efficiency evaluation"). This might be attributable to the short learning time each week (only 1 hour per week). This situation is expected to improve if the CFL learners have more time available to learn the language.

Some items achieved low scores, such as the second one in the dimension of "learning efficiency evaluation" (the mean score for all is 3.2). This was due to the large number of materials contained in the Web PPT and the lack of SL function pointing to a specific item in the Web PPT. One participant even provided some suggestions to improve the problem, as follows.

Good teaching for an online based course but the PPT shown in class needs to be clearer somehow. Maybe number the slides and the sentences in each slide so it will be easier to know exactly what the teacher is referring to. It is much more difficult to get the Chinese pronunciation without the English letters at the bottom.

In the dimension of "peer communication," the reduction in the score for the first item in the third unit compared to the other two was due to an audio problem encountered in that class, as reported by one of the participants, as follows:

In the classroom environment, students need to be aware of the setting for their audio, make sure it is attached to the avatar and not the avatars camera view. It is easy to move too far away from other students or have them situated where it is hard to hear them. Audio in second look is directional and proportional to distance, so while it is easy to be near the teacher/PPT display to hear, it can be difficult to hear a student far behind you.

Furthermore, the busy schedules of the participants also influenced their responses to the questionnaire. One expressed her apologies via email for being unable to find time to finish the assignment because she had to go on a business trip, and she lowered her ranking in the second item in the dimension of "homework evaluation".

In addition to questionnaire responses, the engagement of the participants in the class was also analysed. The videotape analysis revealed that all of the participants engaged in all of the activities with high levels of motivation. They were willing to do all the activities following teacher's guidance: answer questions, perform tasks, and cooperate with their peers. With regard to concentration, only one participant displayed a slow reaction in unit 1 , which was due to Internet connection problems that caused delays in communication or delivery of the teaching material. The problem was resolved by using another connection method (Skype) to instantaneously "rescue" participants from losing the teaching processes. Three of the participants showed high initiative during the units. They did their homework and handed it in to their teacher on time. They were also willing to assist the learning of their peers. Only one participant turned up late or did his homework infrequently. However, from his feedback expressed on the questionnaire, this was attributable to problems with his computer rather than his lack of motivation or interest. The high degree of engagement in the class among the participants was also identified from their positive feedback for the questionnaire. An example of the positive feedback mentioned above follows:

SL is a good environment for virtual learning; it provides an excellent learning environment to create classroom experiences that may not be possible otherwise. I felt it worked extremely well for the Chinese class and kept the engagement level high. It was a comfortable environment for me and was most enjoyable. Getting comfortable in the Second Life environment is the key I feel to getting the most out of the class. 


\begin{tabular}{|c|c|c|c|c|c|}
\hline Activity & Interactions & $\begin{array}{l}\text { SL objects/ } \\
\text { functions }\end{array}$ & SL scenes & $\begin{array}{c}\text { Time } \\
\text { (minutes) }\end{array}$ & Purposes \\
\hline \multicolumn{6}{|l|}{ Vocabulary review: } \\
\hline $\begin{array}{l}\text { The teacherreviewed the vocabulary for } \\
\text { directions by PPT or TPR; pair work was } \\
\text { usedin this activity. }\end{array}$ & $\mathrm{IA}, \mathrm{ACA}$ & $\begin{array}{l}\text { 1. Web PPT } \\
\text { 2.Moving }\end{array}$ & Classroom & 5 & M, I \\
\hline \multicolumn{6}{|l|}{ Sentence review: } \\
\hline $\begin{array}{l}\text { The teacher usedmaps so let students } \\
\text { practice; pair work was used in this activity. }\end{array}$ & $\mathrm{IA}, \mathrm{ACA}$ & 1. Web PPT & Classroom & 5 & $\mathrm{M}, \mathrm{I}$ \\
\hline $\begin{array}{l}\text { New materials for teaching: } \\
\text { transportation } \\
\text { The teacher used a PPT to practice } \\
\text { vocabulary and sentence structures on } \\
\text { transportation; } R \text { P was used in this a ctivity. }\end{array}$ & $\mathrm{IA}, \mathrm{ACA}$ & 1. Web PPT & Classroom & 10 & $\mathrm{E}, \mathrm{M}$ \\
\hline \multicolumn{6}{|l|}{ Treasure-hunting activity: } \\
\hline $\begin{array}{l}\text { 1. Rule explanation } \\
\text { (1) Teacherused a Web PPT in the classroom } \\
\text { to explain the rules. }\end{array}$ & $\mathrm{IA}, \mathrm{ACA}$ & $\begin{array}{l}\text { 1. Web PPT } \\
\text { 2. Teleport }\end{array}$ & $\begin{array}{l}\text { Classroom } \\
\text { Classroom }\end{array}$ & 5 & $\mathrm{E}, \mathrm{N}$ \\
\hline $\begin{array}{l}\text { (2) The participants negotiated with each } \\
\text { other for sharing the tasks. }\end{array}$ & IA & & & & \\
\hline $\begin{array}{l}\text { (1) CFL teacher gave the first hint to the } \\
\text { student andinformed that the nexthint } \\
\text { would be given once the first task was } \\
\text { complete. }\end{array}$ & $\mathrm{IA}, \mathrm{ACA}$ & & Classroom & & \\
\hline 2. Individualmissions & & 1. Teleport & Bus station, & 15 & I \\
\hline $\begin{array}{l}\text { (1) At one stop, the teacher and students } \\
\text { played the game "Simon says." The- } \\
\text { teacher gave the directions, and students } \\
\text { performed the actions. }\end{array}$ & IA & $\begin{array}{l}\text { 2. Note card } \\
\text { 3. Mini map }\end{array}$ & $\begin{array}{l}\text { post office, } \\
\text { library, } \\
\text { supermarket }\end{array}$ & & \\
\hline $\begin{array}{l}\text { The teacher gave note cards to students } \\
\text { performing the correct actions. }\end{array}$ & $\begin{array}{l}\mathrm{IA}, \mathrm{ACA}, \\
\mathrm{AC}\end{array}$ & & & & \\
\hline $\begin{array}{l}\text { (3) In this activity, the CFL teacher watched } \\
\text { the mini map to observe the students'. } \\
\text { movements. }\end{array}$ & $\mathrm{AC}$ & & & & \\
\hline $\begin{array}{l}\text { 3. Figuring out the answer } \\
\text { (1) Students discussed with their peers to } \\
\text { determine the answer by unscrambling the } \\
\text { fournote cards into a correct Chinese- } \\
\text { sentence. }\end{array}$ & $\mathrm{IA}, \mathrm{ACA}$ & $\begin{array}{l}\text { 1. Note card } \\
\text { 2. Teleport }\end{array}$ & Bus station & 10 & $\mathrm{~N}$ \\
\hline \multicolumn{6}{|l|}{ 4. Finding the treasure } \\
\hline (1) The teacher teleported to the destination. & $\mathrm{AC}$ & 1. Teleport & Hotel, & 10 & $\mathrm{~N}$ \\
\hline (2) Preparing presents: a luggage bag. & $\mathrm{AC}$ & 2.Mini map & Hotel room & & \\
\hline $\begin{array}{l}\text { (3) The teacher watched the mini map to } \\
\text { observe the students' moves. }\end{array}$ & $\mathrm{AC}$ & $\begin{array}{l}3 . \text { Object } \\
\text { transmission }\end{array}$ & & & \\
\hline $\begin{array}{l}\text { (1) Give presents to students after they found } \\
\text { the correct location. }\end{array}$ & IA, ACA & & & & \\
\hline
\end{tabular}

Figure 8. Results of video data analysis of the different interactions in the expansion stage of the unit "怎 麼去" ("How to get there"). 
Conversation 1 was in a supermarket and involved a CFL learner (L) and salesclerk (S) as the interlocutors:

[00:00:00.00] L: 漢堡和餅乾一共多少錢? (How much are a hamburger and a cookie?) [00:00:09.64] S: 一共六元. (It is six dollars.).

[00:00:16.93] S: You still want 漢堡 and 可樂, right? (You still want the hamburgers and Coke, right?) [00:00:26.49]L: Yes.

[00:00:28.87] S: So 一共七元, of all the things you buy, ok? (So it is 7 dollars, of all the things you buy, ok?)

[00:00:39.22]L: OK，漢堡多少錢? (How much is a hamburger?)

[00:00:47.80] S: 漢堡二元. (A Hamburger is 2 dollars.)

[00:00:53.39] L: 餅乾一元? (A cookie is 1 dollar?)

[00:00:59.66] S: 餅乾四元. (A cookie is 4 dollars.)

[00:01:08.42]L: 可樂多少䤦? (How much is the Coke?)

[00:01:13.29] S: 可樂一元. (Coke is 1 dollar.)

[00:01:15.97]L: 可樂一元. (Coke is 1 dollar.)

[00:01:20.35] S: 一共七元. (That's 7 dollars.)

[00:01:24.01] L: OK, 一共七元. (OK, it is 7 dollars.)

Conversation 2 was in a classroom and involved two CFL learners (L1 \& L2) and the teacher $(\mathrm{T})$ as the interlocutors:

[00:00:00.40] T: Is also the review part. Since you know what is 喜歡(like). OK, and this is the food part. 記得嗎? (Do you remember?)

[00:00:21.35]L1: 我喜, 我喜歡雞肉. (I like, I like chicken.)

[00:00:25.72] T: 雞肉, Ok. L2 你喜歡什麼? (Chicken. OK. L2, what do you like?)

[00:00:34.81]L1：我不喜歡...嗯 (I don't like. $m m$ )...I forget what banana is. Ok, the other, 我不喜歡蘋果. (I don't like apples.)

[00:00:56.85] T: 喔 你不喜歡蘋果. So, L2? (Oh, you don't like apples)

[00:01:01.78] L2: 我喜歡蘋果. (I like apples)

[00:01:02.38] T:L1 喜歡雞肉不喜歡蘋果. L2 喜歡頻果. (L1 likes chicken but doesn't like apples. L2 likes apples.)

Figure 9. Two conversation examples. 
Research question 2: What kinds of social interactions emerge from the learning activities in the CFL class in SL?

The video data analysis revealed three categories of social interactions in study 2 that had already been found in study 1: IA, AC, and ACA. However, quite different activities were run in the two studies: far more teacher-centred activities were identified in study 1, while a high proportion of student-centred activities were found in study 2. In order to clearly present how the learning activities inspired CFL learners to socially interact with peers, the expansion stage of the unit "怎麼去" ("How to get there") served as an example to detail the activity purposes, identified social interactions, and used SL functions/objects and scenes of each activity did in the E stage, as shown in Figure 8. In addition, results similar to those presented in Figure 8 were found in all nine lessons based on video data observation.

Additionally, it was found that the text function was used much less frequently, and many more interparticipant oral conversations were found in IA interactions. In addition to cooperation activities, peerassisted learning activities were identified in study 2. For example, in the unit of colour party, one participant shared what he bought from Freebies with his peer participants when he found that he did not find the correct clothes for the party.

Research question 3: How do those activities benefit CFL learners to learn Chinese in SL?

The video data analysis revealed that a high proportion of student-centred activities increased the motivation of CFL learners, as expected. In addition, they also effectively helped to keep the attention of CFL learners in the classroom. One participant mentioned that she appreciated the learning experience in her feedback, as follows:

In the class, the students could work together to solve problems and experience simulated scenarios (like the shopping, restaurant or location finding) with more time and the teaching staff available as facilitators and to answer questions. This may offer more learning scenarios like a treasure hunt, e.g., where successfully decoding a notecard leads you to another notecard and another piece of the solution.

Analysis of the IA conversations revealed that most of the conversations that took place in study 2 were more fluent than those in study 1, with the exception of difficulties due to poor audio or internet connection quality. The interaction goal was reached within a small number of both turns and moves, and fluent grounding. The discourses shown in Figure 9 are examples of two conversations. In addition, the italic English sentences in parentheses are the corresponding translations of the Chinese sentences.

The fluency of in-class conversations, and the social interactions (either verbal or nonverbal), homework, and in-class oral performances of CFL learners were analysed in addition to the attitudes of the participants. The oral performance of the participants was the main concern while in class. In addition to the measured total spoken word length (one way or two ways), the error patterns and the frequency of mispronunciation were also assessed. On the other hand, the accuracy of using the target language was one of the main parameters used to assess various abilities (listening, reading, and speaking) in homework performances. All the data were coded by two qualified CFL teachers. The Pearson product-moment correlation of the frequencies of various performances computed from the two copies of the records was 0.99. Table 2 gives the data for the average in- and after-class performances of all participants in different lessons.

Table 2

Average CFL performance in different lessons

\begin{tabular}{|c|c|c|c|c|c|c|c|c|c|c|}
\hline & \multirow{2}{*}{\multicolumn{3}{|c|}{$\begin{array}{l}\text { Unit } 1 \\
\text { Are you hungry? }\end{array}$}} & \multirow{2}{*}{$\begin{array}{l}\text { Unit } 2 \\
\text { How } \\
\text { there? }\end{array}$} & \multirow[b]{2}{*}{ do you } & & \multirow{2}{*}{\multicolumn{3}{|c|}{$\begin{array}{l}\text { Unit } 3 \\
\text { Colour party }\end{array}$}} \\
\hline & & & & & & & & & & \\
\hline & & $\mathrm{C}$ & $\mathrm{U}$ & $\mathrm{E}$ & $\mathrm{C}$ & $\mathrm{U}$ & $\mathrm{E}$ & $\mathrm{C}$ & $\mathrm{U}$ & $\mathrm{E}$ \\
\hline \multicolumn{2}{|c|}{ Homework (accuracy) } & $89.8 \%$ & $95 \%$ & $95 \%$ & $88.8 \%$ & $89.5 \%$ & $95 \%$ & $90 \%$ & $85 \%$ & $95 \%$ \\
\hline \multirow[t]{2}{*}{$\begin{array}{l}\text { In } \\
\text { class }\end{array}$} & $\begin{array}{l}\text { Number of } \\
\text { mispronounced words }\end{array}$ & 2 & 6 & 0.5 & 1 & 1 & 1 & 3 & 0 & 2.5 \\
\hline & $\begin{array}{l}\text { Total number of spoken } \\
\text { words }\end{array}$ & 152 & 256 & 313 & 182 & 201 & 168 & 217 & 235 & 177 \\
\hline
\end{tabular}


It was found that the participants made progress in homework performance in each unit, whereby they achieved 100 points in reading items in every assignment. Furthermore, they made surprising progress in their speaking. Their oral speaking recordings (one of the items in the homework) indicated that the longest sentence they uttered in the first assignment consisted of 12 Chinese characters (syllables), while they uttered 34 Chinese characters (syllables) in their longest sentence in the last assignment. Furthermore, two mispronounced vowels and one error tone were heard in the longest sentence of the first assignment, but only one error tone and no vowel or consonant errors were heard in the longest sentence of the last assignment.

Regarding the in-class performance of the participants, they frequently spoke Chinese in class, either with the teacher's guidance or via IA oral interactions. It is noteworthy that the total length of words used in oral interactions did not increase in two-thirds of the lessons in both the second and third units; the participants actually proceeded with more socially interactive tasks in the expansion stage of the two units than in the cognition or usage stages of the same units or the first unit. Furthermore, the CFL learners had to accomplish many more individual missions (e.g., shopping for clothes in Freebies) for both the usage and expansion stages in the latter two units ("how do you get there?" and "colour party"), and consequently the quantity of speech decreased. It is noteworthy that the performance of the participants in correct pronunciation of Chinese vowels and consonants also improved in study 2.

\section{Discussion}

The purposes of this research were to elucidate (1) the efficacy of a CFL teaching model in SL with language learning activities designed to better elicit meaningful interactions between CFL learners in virtual worlds and (2) the attitudes of CFL learners toward Chinese learning in SL. Comparison between studies 1 and 2 performed to accomplish these purposes revealed that an activity considered to be effective for eliciting social interactions and oral communications in a virtual CFL class needs to meet the criteria described below.

First, the prior skills of the participants need to be taken into account. The language focus of every unit was introduced in the cognition stage of the CUE model and was mastered via different activities during the three stages. This improved upon the problems encountered in study 1 and is consistent with the finding of Lan, Sung, abd Chang (2009) that insufficient language skills will affect the ability of beginners to complete tasks and perform inter-peer interactions. Therefore, cultivating the basic linguistic skills of learners at an early stage is essential. This is also in line with Nunan (2004) arguing that schema building is the first step of the TBL of languages toward developing a language-learning task.

Pronunciation and tone are other necessary prior Chinese language skills, especially for CFL beginners. Mandarin Chinese comprises four pitched and one "toneless" tone. Therefore, with the different tones, only one syllable can represent four different Chinese characters. Pre-CUE training was conducted to provide the CFL beginners with basic Hanyu Pinyin knowledge in study 2. This preparation did help the participants to follow the teacher's instructions and guidance in class from the first lesson. However, even though the pronunciation was better in study 2 than in study 1 , some tone errors made by participating CFL beginners remained throughout the lessons, especially with respect to the first tone. This problem may be solved by making available streaming videos showing clear mouth movements to help students to pronounce correct Chinese phonemes during virtual CFL classes.

Second, the relevance between the learning activity and the SL scenes greatly impacts the grounding of social interactions and conversations. This finding echoes the ecological perspective in which the environment plays an important role in the emergent process of meaning-making in addition to signs, the self, and the other (van Lier, 2004). SL learners in a poor linguistic environment will encounter difficulties acquiring the language. Similarly, they will also struggle with inconsistent SL scenes/contexts in determining what happens in the virtual CFL class.

Third, clear activity sequencing should be also taken into account in task design. According to the findings of this research, not only does the activity itself but also the sequence in which it is executed in the CFL class influence the fluency of social interactions and IA conversations. It is suggested that introduction of prior skills should be followed by individual rather than cooperative tasks, despite 
cooperation almost always being recommended in language learning based on the social constructivism perspective (Vygotsky, 1978). Furthermore, although the proposed CUE model seems similar to the presentation-practice-production (PPP) model at first glance, they are grounded on different SLA foundations. The PPP model has its origins in audio-lingualism emphasizing form-focus and controlled practice after basic skills introduced with the aim of helping learners transfer descriptive knowledge to procedure knowledge of the target language (Sato, 2010; Shintani, 2011); while the CUE model highlights learners' manipulation of the target language via meaning-based social interaction (IA, AC, or ACA) during task accomplishing processes. In addition, the CUE model regards CFL teachers' timely support as an important component to ensure that each individual is able to accomplish assigned tasks successfully. This finding expands the framework for task design proposed by Jauregi et al. (2011) and could serve as a good reference for CFL researchers designing learning activities.

The questionnaire responses and feedback obtained from study 2 revealed that the CFL learners had positive attitudes toward Chinese learning in SL. The video data analysis also revealed their high motivation, continuous concentration, and ability to act on their own initiative. The positive tendency regarding the affective dimension found in this research is not only in line with many other studies of SL, such as those of Liou (2012) and Henderson et al. (2009), but also furthers the understanding of affordances of SL for CFL teaching/learning. The current research conducted a CFL class completely implemented in SL, not just one teaching medium option or a supplement to a regular CFL class in a traditional environment. The experiences in activity design and online leadership to uphold the motivation and attendance of participants at the virtual CFL class are worthy of reference to related research. In response to the negative comments of participants about SL and a CFL learning platform, Chen (2010) emphasized the importance of activity design for encouraging students to explore the SL virtual world and to sustain their motivation for repeated exploration.

In addition to the findings discussed above, the two most concerning issues encountered in this research should be investigated further by FL educators and researchers: (1) providing CFL learners with irregular learning time slots and authentic learning tasks in SL simultaneously, and (2) increasing the confidence of CFL learners in transferring what is learned in SL to the real world. One possible solution to this challenge would be to develop an intelligent context-awareness learning environment in SL. In addition to this context-awareness technique, and similar to mobile learning, some other techniques (e.g., speech recognition and automated assessment) are also needed in such an intelligent CFL learning environment. Therefore, cross-discipline cooperation is required in future research.

\section{Conclusion and future research}

The aim of this research was to elucidate the principle of activity design for CFL teaching/learning in SL. Analysis of the video data revealed that the participants had positive attitudes toward the learning activities. In addition, three criteria for designing activities were suggested. We conclude that the CUE model fulfils these criteria and could serve as a good reference for related research. In addition, some suggestions are made for future research: (1) the development and evaluation of streaming video for Chinese pronunciation learning, and (2) the development of an intelligent context-awareness learning environment to provide CFL learners with irregular learning time slots and to increase their confidence in using what has been learned in SL in the real world.

The sample in this research was small, and hence an expansion of this preliminary research is planned with CFL beginners from Griffith University, Australia. Students will be grouped into three groups, each with a different learning design, and the learning performances of the different groups will be compared to identify the efficiency of the CUE model in CFL teaching/learning in SL.

With contextualized and meaningful interactions and communications, FL learning is no longer achieved by merely rote learning or recitation. There is no doubt that SL has great potential in this field, but further efforts are required to give it a significant role in connecting students for social and authentic FL learning. The findings obtained in this research offer insights for CFL teachers and researchers who are designing learning activities in SL, thereby ushering in a new era for virtual FL learning and teaching. 


\section{Acknowledgments}

The authors would like to thank the National Science Council of the Republic of China, Taiwan, for financially supporting this research under Contract Nos. NSC 101-2511-S-003-031-MY3 and NSC972631-S-003-002. The authors also want to thank the Ministry of Education of the Republic of China, Taiwan, for financially supporting this research under Aim for the Top University Plan. Additionally, we thank colleagues from the Institute for Information Industry for their technical support in Study 1.

\section{References}

Bruner, J. (1977). The process of education. London: Harvard University Press.

Chen, D. (2010). Enhancing the learning of Chinese with Second Life. Journal of Technology and Chinese Learning Teaching, 1(1), 14-30.

Clark, H. H., \& Brennan, S. A. (1993). Grounding in communication. In L. B. Resnick, J. M. Levine, \& S. D. Teasley (Eds.). Perspectives on socially shared cognition. Washington: APA Books.

Collentine, K. (2011). Learner autonomy in a task-based 3D world and production. Language Learning \& Technology, 15(3), 50-67.

Conklin, M. S. (2007). 101 uses for Second Life in the college classroom. Retrieved from http://warburton.typepad.com/disruptive/documents/SL_handout.pdf

Cooke-Plagwitz, J. (2008). New directions in CALL: An objective introduction to Second Life. CALICO Journal, 25(3), 547-557.

Dalgarno, B., \& Lee, M. J. W. (2010). What are the learning affordances of 3-D virtual environments? British Journal of Educational Technology, 41(1), 10-32.

Dalgarno, B., Lee, M. J. W., Carlson, L., Gregory, S., \& Tynan, B. (2011). An Australian and New Zealand scoping study on the use of 3D immersive virtual worlds in higher education. Australasian Journal of Educational Technology, 27(1), 1-15.

Deutschmann, M., Panichi, L., \& Molka-Danielsen, J. (2009). Designing oral participation in Second Life - a comparative study of two language proficiency courses. ReCALL, 21(2), 206-226.

e-Learning quality certification center (2007a). E-Learning service certification-specification clauses. Retrieved from http://www.elq.org.tw/en/els01.php.

e-Learning quality certification center (2007b). E-Learning courseware certification-specification clauses. Retrieved from http://www.elq.org.tw/en/elc02.php

Ellis, R. (2000). Task-based research and language pedagogy. Language Teaching Research, 4(3), 193220.

Grant, S. (2010). About Monash Chinese Island. Retrieved from http://www.virtualhanyu.com/?page_id=87

Henderson, M., Huang, H., Grant, S, \& Henderson, L. (2009). Language acquisition in Second Life: Improving self-efficacy beliefs. In Same places, different spaces. Proceedings ascilite Auckland 2009. Retrieved from http://www.ascilite.org.au/conferences/auckland09/procs/henderson.pdf

Hew, K. F., \& Cheung, W. S. (2010). Use of three-dimensional (3-D) immersive virtual worlds in K-12 and higher education settings: A review of the research. British Journal of Educational Technology, 41(1), 33-55. 
Hundsberger, S. (2009). Foreign Language learning in Second Life and the implications for resource provision in academic libraries. Retrieved from http://arcadiaproject.lib.cam.ac.uk/docs/second_life.pdf

Jauregi, K., Canto, S., de Graaff, R., Koenraad, T., \& Moonen, M. (2011). Verbal interaction in Second Life: Towards a pedagogic framework for task design. Computer Assisted Language Learning, 24(1), 77-101.

Jarmon, L., Traphagan, T., Mayrath, M., \& Trivedi, A. (2009). Virtual world teaching, experiential learning, and assessment: An interdisciplinary communication course in Second Life. Computers \& Education, 53, 169-182.

Krashen, S. D. (1981). Second language acquisition and second language learning. USA: Pergamon Press.

Lan, Y. J., Sung, Y. T., \& Chang, K. E. (2009). Let us read together: Development and evaluation of a computer assisted reciprocal early English reading system. Computers \& Education, 53(4), 11881198.

Lave, J., \& Wenger, E. (1991). Situated learning legitimate peripheral participation. NY: Cambridge University Press.

Lewis, M. P., Simons, G. F., \& Fennig, C. D. (Eds.). (2013). Ethnologue: languages of the world (17th ed). Dallas, Texas: SIL International. Retrieved from http://www.ethnologue.com/show_language.asp?code $=\mathrm{cmn}$

Liou, H. C. (2012): The roles of Second Life in a college computer assisted language learning (CALL) course in Taiwan, ROC. Computer Assisted Language Learning, 25(4), 365-382. doi:10.1080/09588221.2011.597766.

Liu, S. (2010). Second Life and its application in Chinese teaching and learning. Journal of Technology and Chinese Learning Teaching, 1(1), 71-93.

Long, M. H. (1996). The role of the linguistic environment in second language acquisition. In W. C. Ritchie, \& K. B. Tej (Eds.), Handbook of second language acquisition (pp. 413-468). San Diego: Academic Press.

Nunan, D. (2004). Task-based language teaching. UK: University Press, Cambridge.

Oblinger, D., \& Oblinger, J. (2005). Educating the net generation. Boulder, CO: Educause.

Peterson M. (2008). Virtual worlds in language education. The JALT CALL Journal, 4(3), 29-36.

Sadler, R., \& Nurmukhamedov, U. (2008, March). Second Life and task-based learning. Paper presented at CALICO annual conference, San Francisco, CA.

Sato, R. (2010). Reconsidering the effectiveness and suitability of PPP and TBLT in the Japanese EFL classroom. JALT Journal, 32(2), 189-200.

Shintani, N. (2011). Task-based language teaching versus traditional production-based instruction: Do they result in different classroom processes? TESOL, 6, 97-120.

Stevens, V. (2006). Second life in education and language learning. TESL-EJ, 10(3). Retrieved from http://tesl-ej.org/ej39/int.pdf

Swain, M. (1995). Three functions of output in second language learning. In G. Cook, \& B. Seidelhofer, (Eds.), Principle and practice in applied linguistics: Studies in honour of H.G. Widdowson (pp. 125144). Oxford: Oxford University Press. 
Thorne, S. L., Black, R. W., \& Sykes, J. M. (2009). Second language use, socialization, and learning in Internet interest communities and online game. The Modern Language Journal, 93, 802-823.

Time Asia (2006). Get ahead, learn mandarin: China's economic rise means the world has a new second language - and it isn't English. Retrieved from http://www.time.com/time/asia/covers/501060626/story.html

van Lier, L. (1996). Interaction in the language curriculum: Awareness, autonomy and authenticity. London: Longman.

van Lier, L. (2004) The ecology and semiotics of language learning: a sociocultural perspective. Dordrecht: Kluwer Academic Publishers.

Vygotsky, L. (1978). Mind in society: The development of higher psychological process. Cambridge, MA: Harvard University Press.

Corresponding author: Kuo-En Chang, kchang@ntnu.edu.tw

Australasian Journal of Educational Technology (C) 2013.

Please cite as: Lan, Y.-J., Kan, Y.-H., Hsiao, I. Y. T., Yang, S. J. H., \& Chang, K.-E. (2013) Designing interaction tasks in Second Life for Chinese as a foreign language learners: A preliminary exploration. Australasian Journal of Educational Technology, 29(2), 184-202. 